\title{
Sutureless technology for aortic valve replacement: Looking beyond crossclamp time
}

\author{
Mattia Glauber, MD, Antonio Lio, MD, and Antonio Miceli, MD, PhD
}

\author{
From the Centro Cardiotoracico, Istituto Clinico Sant'Ambrogio, Gruppo Ospedaliero San Donato, Milan, Italy. \\ Disclosures: Authors have nothing to disclose with regard to commercial support. \\ Received for publication Jan 22, 2016; accepted for publication Jan 23, 2016. \\ Address for reprints: Mattia Glauber, MD, Via Luigi Giuseppe Faravelli, 16, 20149 Milan, Italy (E-mail: mattia. \\ glauber@gmail.com). \\ J Thorac Cardiovasc Surg 2016;151:1637-8 \\ 0022-5223/\$36.00 \\ Copyright (C) 2016 Published by Elsevier Inc. on behalf of The American Association for Thoracic Surgery \\ http://dx.doi.org/10.1016/j.jtcvs.2016.01.036
}

We read with great interest the recent article by Forcillo and colleagues. ${ }^{1}$ Aortic valve stenosis is emerging as the most common valve disease in Western countries because of a rapidly aging population. ${ }^{2}$ To reduce operative morbidity and mortality and to expand the indication of treatment for high-risk patients, innovative technologies recently have emerged, such as sutureless prostheses. Sutureless valves have shown excellent clinical and hemodynamic outcomes, no structural valve deterioration, and high freedom from valve reoperation as late as 5 years. ${ }^{3-5}$

Sutureless technology maintains the advantage of removing the diseased valve and reduces the need for sutures after annular decalcification, reducing aortic crossclamp and cardiopulmonary bypass (CPB) times. Ranucci and colleagues ${ }^{6}$ reported that the aortic crossclamp time is an independent predictor of severe cardiovascular morbidity, with an increased risk of $1.4 \%$ per 1 -minute increase. Although there are many data supporting reduced surgical operative times with sutureless valves in patients undergoing aortic valve replacement (AVR), whether the use of this technology results in improved outcomes is still debated. In their work, Forcillo and colleagues, ${ }^{1}$ comparing sutureless and stented valves in a population aged more than 80 years, did not find any difference between groups in terms of mortality and morbidities.

In our opinion, in cases of short duration of cardiac arrest ischemic time ( $<60$ minutes), such as isolated AVR, benefits of a further reduction with sutureless valves implantation might not be evident when a good myocardial protection could be achieved. Conversely, in the presence of concomitant procedures with expected long CPB and crossclamp times, sutureless technology has the potential to reduce the complications and morbidity of long surgical times. ${ }^{7,8}$ Moreover, the use of sutureless prostheses may be recommended in high-risk procedures, such as patients with prior implantation of aortic homograft and stentless valves, in redo procedures, or in the presence of calcified root or porcelain aorta, when possible technical problems in myocardial protection may coexist. ${ }^{9-11}$

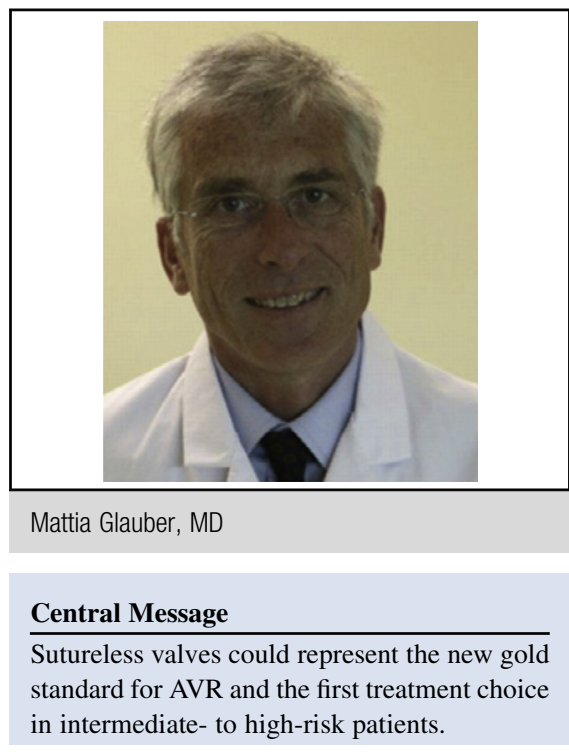

See Article page 1629.

Sutureless valves also may enhance minimally invasive AVR (MIAVR). The main limitation of MIAVR is represented by the longer CPB and crossclamp times compared with conventional surgery because of the reduced working space. The adoption of sutureless technology might remove the drawback of increased surgical times. In their work, Forcillo and colleagues ${ }^{1}$ have found a significant increase of MIAVR with sutureless valves $(P=.034)$, but a comparison with AVR through full sternotomy with stented bioprostheses was not performed. In a large series of 515 AVRs through a right minithoracotomy, we have found that sutureless valve implantation was associated with a shorter duration of mechanical ventilation (7 vs 6 hours, $P=.001$ ). Moreover, in elderly patients (aged $>82$ years) selected from the propensity-matched population, there was a significant survival benefit in the sutureless group ( $100 \%$ vs $50 \% P=.02$ ), also selecting patients with a follow-up restricted to 40 months or less $(78.6 \%$ vs $97 \%$, $P=.002){ }^{12}$ Another field of interest for sutureless technology is represented by patients with small or critically small aortic annuli, in whom implantation of this new device allows maximization of the bioprosthetic diameter. ${ }^{13}$ In the largest series of sutureless valves, Shrestha and colleagues ${ }^{4}$ showed that in patients with a small aortic annulus, the postoperative transvalvular gradients were low and remained stable over time up to the 5-year follow-up. These 
data have been confirmed by a recent prospective cohort study, in which these valves reduced the risk of patientprosthesis mismatch after AVR. ${ }^{14}$

Concern exists about the increased risk of postoperative conduction disorders with the use of sutureless prostheses. ${ }^{15,16}$ Forcillo and colleagues ${ }^{1}$ reported a rate of pacemaker implantation of $17 \%$, which is higher than reported in the literature. ${ }^{4,17,18}$ Pacemaker implantation after AVR depends on several factors, such as variability among cardiologists for the indication, and so it is difficult to define the real incidence. However, a recent meta-analysis has shown that the pooled estimates of pacemaker implantation for sutureless prostheses were comparable to pooled estimates for conventional AVR. ${ }^{17}$ Vogt and colleagues, ${ }^{19}$ trying to identify the risk factors of postoperative conduction disorders in patients undergoing sutureless AVR, found preoperative right bundle branch block and surgeon's learning curve as independent predictors. By gaining familiarity with these new devices, we have found a lower incidence of pacemaker implantation that is comparable to conventional stented valves. $^{10,12,18}$

The excellent results reported in the literature and the increase in minimally invasive procedures associated with this new technology place sutureless prostheses as the potential new gold standard for AVR and the first treatment choice in intermediate- to high-risk patients, filling the gap between transcatheter aortic valve implantation and traditional AVR.

\section{References}

1. Forcillo J, Bouchard D, Nguyen A, Perrault L, Cartier R, Pellerin M, et al. Perioperative outcomes with sutureless versus stented biological aortic valves in elderlies. J Thorac Cardiovasc Surg. 2016;151:1629-36.

2. Vahanian A, Otto CM. Risk stratification of patients with aortic stenosis. Eur Heart J. 2010;31:416-23.

3. Englberg L, Carrel TP, Doss M, Sadowski J, Bartus K, Eckstein FF, et al. Clinical performance of a sutureless aortic bioprosthesis: five-year results of the $3 \mathrm{f}$ Enable long term follow-up study. J Thorac Cardiovasc Surg. 2014;148:1681-7.

4. Shrestha M, Fischlein T, Meuris B, Flameng W, Carrel T, Madonna F, et al. European multicentre experience with the sutureless Perceval valve: clinical and haemodynamic outcomes up to 5 years in over 700 patients. Eur J Cardiothorac Surg. 2016;49:234-41.

5. Haverich A, Wahlers TC, Borger MA, Shrestha M, Kocher AA, Walther T, et al. Three-year hemodynamic performance, left ventricular mass regression, and prosthetic-patient mismatch after rapid deployment aortic valve replacement in 287 patients. J Thorac Cardiovasc Surg. 2014;148:2854-60.

6. Ranucci M, Frigiola A, Menicanti L, Castelvecchio A, De Vincentiis C, Pistuddi V, et al; for the Surgical and Clinical Outcome Research (SCORE) Group. Aortic cross-clamp time, new prostheses, and outcome in aortic valve replacement. J Heart Valve Dis. 2012;21:732-9.

7. Shrestha M, Folliguet TA, Pfeiffer S, Meuris B, Carrel T, Bechtel M, et al. Aortic valve replacement and concomitant procedures with the Perceval valve: results of European trials. Ann Thorac Surg. 2014;98:1294-300.

8. Ferrari E, Siniscalchi G, Marinakis S, Berdajs D, von Segesser L. 'Fast-implantable' aortic valve implantation and concomitant mitral procedures. Interact CardioVasc Thorac Surg. 2014;19:682-4.

9. Pollari F, Santarpino G, Dell'Aquila AM, Gazdag L, Alnahas H, Vogt F, et al. Better short-term outcome by using sutureless valves: a propensity-matched score analysis. Ann Thorac Surg. 2014;98:611-6.

10. Glauber M, Miceli A, Gilmanov D, Ferrarini M, Bevilacqua S, Farneti PA, et al. Right anterior minithoracotomy versus conventional aortic valve replacement: a propensity score matched study. J Thorac Cardiovasc Surg. 2013;145:1222-6.

11. Villa E, Messina A, Cirillo M, Brunelli F, Mhagna Z, Dalla Tomba M, et al. Perceval sutureless valve in freestyle root: new surgical valve-in-valve therapy. Ann Thorac Surg. 2013;96:e155-7.

12. Gilmanov D, Miceli A, Ferrarini M, Farneti PA, Murzi M, Solinas M, et al. Aortic valve replacement through right anterior minithoracotomy: can sutureless technology improve clinical outcomes? Ann Thorac Surg. 2014;98:1585-92.

13. Shrestha M, Maeding I, Hoffler K, Koigeldiyev N, Marsch G, Siemeni T, et al. Aortic valve replacement in geriatric patients with small aortic roots: are sutureless valves the future? Interact CardioVasc Thorac Surg. 2013;17:778-82.

14. Bonderman D, Graf A, Kammerlander AA, Kocher A, Laufer G, Lang IM, et al. Factors determining patient-prosthesis mismatch after aortic valve replacement-a prospective cohort study. PLoS One. 2013;8:e81940.

15. van Boxtel AG, Houthuizen P, Hamad MA, Sjatskig J, Tan E, Prinzen FW, et al. Postoperative conduction disorders after implantation of the self-expandable sutureless Perceval S bioprosthesis. J Heart Valve Dis. 2014;23:319-24.

16. Santarpino G, Pfeiffer S, Jessl J, Dell'Aquila AM, Pollari F, Pauschinger M, et al. Sutureless replacement versus transcatheter valve implantation in aortic valve stenosis: a propensity-matched analysis of 2 strategies in high-risk patients. $J$ Thorac Cardiovasc Surg. 2014;147:561-7.

17. Phan K, Tsai YC, Niranjan N, Bouchard D, Carrel TP, Dapunt OE, et al. Sutureless aortic valve replacement: a systematic review and meta-analysis. Ann Cardiothorac Surg. 2015;4:100-11.

18. Miceli A, Santarpino G, Pfeiffer S, Murzi M, Gilmanov D, Concistrè G, et al. Minimally invasive aortic valve replacement with Perceval S sutureless valve: early outcomes and one-year survival from two European centers. J Thorac Cardiovasc Surg. 2014;148:2838-43.

19. Vogt F, Pfeiffer S, Dell'Aquila AM, Fischlein T, Santarpino G. Sutureless aortic valve replacement with Perceval bioprosthesis: are there predicting factors for postoperative pacemaker implantation? Interact CardioVasc Thorac Surg. 2016;22:253-8. 